\title{
MYCOTOXINS OF 'TORTILLAS', ITS CARCINOGENIC AND CYTOTOXIC EFFECTS.
}

\section{M.CARVAJAL 1, L.CAMPOS 2, P.PEREDA 1, G.VALENCIA 3, T.R.IRVIN 4 and K.C.}

DONNELLY 5.

1 Department of Botany, Institute of Biology, National Autonomous University of Mexico (UNAM), Apartado Posta1 70-233, 04510 Mexico,D.F.

2 National Autonomous University of Guadalajara, Jalisco,Mexico.

3 Laboratory of Statistics, Department of Mathematics, Faculty of Sciences, UNAM.

4 Department of Veterinary Anatomy,College of Veterinary Medicine,Texas A\&M University,U.S.A.

5 Environmental Mutagenesis Laboratory, Soil and Crop Science Department, Texas A\&M University, U.S.A.

Tortillas are the staple food of Mexico, and the sanitation of them is very important for the health. The aims of this work are the detection of mycotoxins in tortillas; the carcinogenic effect of mycotoxins and the cytotoxic effects. The mexican corn has field and storage fungi that are toxigenic species of Fusarium and Aspergillus.

From February (1986) to April (1987) a survey of the mycotoxins of tortillas was realized, $214 \mathrm{~kg}$ from 83 shops were analyzed, on 5 different sampling days. Each time, one $\mathrm{kg}$ of tortillas was purchased from each one of 36 to 50 shops for analysis. The wet and dry weights of each sample were recorded; thin layer chromatography (TLC) was realized with different methods (ref.1,2) having 6 replications for each sample. The statistical method considered that the work had random variables of Bernoulli type and a bayesian point of view was used for the analysis (ref.3). The Cuauhtemoc District was the one studied, it was chosen because it is the old city of Mexico, has the biggest number of tortilla shops and it has the highest population with all social classes included.

The results of this part of the study are presented in Table 1.

Table 1: Mycotoxins of the Cuauhtemoc District of Mexico city.

\begin{tabular}{|c|c|c|c|c|c|c|}
\hline \multirow[t]{3}{*}{ Mycotoxins } & \multicolumn{5}{|c|}{$\begin{array}{l}\text { Sampling dates with the number of } \\
\text { contaminated samples (one } \mathrm{kg} \text { each) }\end{array}$} & \multirow[t]{3}{*}{$\begin{array}{l}\text { Total of contaminated } \mathrm{kg} / \\
\text { Total of analyzed } \mathrm{kg}\end{array}$} \\
\hline & \multirow[b]{2}{*}{ Feb } & \multicolumn{2}{|r|}{1986} & & \multirow{2}{*}{$\begin{array}{l}1987 \\
\text { Apr }\end{array}$} & \\
\hline & & May & Aug & Nov & & \\
\hline Zearalenone & 1 & 1 & 1 & 1 & 2 & $6 / 214$ \\
\hline Aflatoxin B1 & 3 & 2 & 0 & 0 & 1 & $6 / 214$ \\
\hline Aflatoxin B2 & 2 & 1 & 0 & 0 & 1 & $\begin{array}{l}\text { Aflatoxin B2 was in the } \\
\text { same kg than Aflatoxin B1 }\end{array}$ \\
\hline Aflatoxin G1 & 0 & 0 & 0 & 0 & 0 & None \\
\hline Aflatoxin G2 & 0 & 0 & 0 & 2 & 1 & $3 / 214$ \\
\hline Kg per survey & 35 & 50 & 36 & 61 & 32 & Total $=$ \\
\hline
\end{tabular}

The Aflatoxin B2 (AFB2) was present in the same $\mathrm{kg}$ that had Aflatoxin B1 (AFB1), but not always; the Aflatoxin G1 (AFG1) was not recorded. Sometimes the same kg had zearalenone $(\mathrm{Z})$ and aflatoxins. With a probability of 0.95 it was proved 
that there is a possibility of buying contaminated tortillas in Mexico City because the Cuahtemoc District is a good representat of it. The $89 \%$ of the recorded one $\mathrm{kg}$ samples had a wet weight between 460 to $999 \mathrm{~g}$.

The mutagenic and carcinogenic properties of mycotoxins AFB1, AFB2,Z, Zearalenol (Z1), Deoxynivalenol (DON) and extractions of Fusarium subglutinans of Zacatecas 218 corn with sprouting, were analyzed with the Ames test (ref.4). Salmonella typhimurium line TA 98 was used, which lacks hystidine and does not reproduces itself very much, only when a mutagenic substance is applied, it mutates forming reverted colonies that show how mutagenic or carcinogenic a compound is, depending on the number of colonies.The results were that AFB1 is a severe carcinogenic substance (1298 colonies), AFB2 is a moderate carcinogenic compound ( 125 colonies), $\mathrm{Z}$ is not carcinogenic ( 47 colonies) neither $\mathrm{Z1}$ (47 colonies), DON ( 54.5 colonies)nor $\mathrm{F}$. subglutinans extracts (40,43and 47 colonies) in comparison with the solvant dimethylsulphoxide control ( 36.8 colonies). The cytotoxic effect of the mycotoxins DON, and F.subglutinans extracts from sprouted corn on rat embryo cultures in vitro, of 10 days of development, was recorded taking into account the crown-rump lenght, heart beat, yolk sac circulation, presence of limb buds, number of somites and every malformation,after 2 days. The Irvin-Mertes method was used. The results were that DON (6 ppm) killed the embryos, the $\mathrm{F}$. subglutinans extracts produced alterations in the tail, heart, neurotube, cysts, hemorrhages and malformed embryos.

\section{REFERENCES}

1 L.Stoloff, S.Nesheim,L.Yin, J.V.Rodricks, M.Stack and A.D.Campbe11, A multimycotoxin detection method for aflatoxins, ochratoxins, zearalenone, sterigmatocystin and patulin, J.Assoc.0ff.Anal.Chem.54,(1971) 91-97.

2 F.Thomas, R.M.Eppley and M.W.Trucksess, Rapid screening method for aflatoxins and zearalenone in corn, J.Assoc.Off.Anal.Chem.58(1), (1975) 114-116.

3 J.M.Bernardo, Reference posterior distributions for Bayesian Inference, J. Royal Statistical Soc. 41, (1979) 113-147.

4 B.N.Ames, J.McCann and E.Yamasaki, Methods for detecting carcinogens and mutagens with the Salmonella/Mammalian microsome mutagenicity test, Mutation $\mathrm{Re}-$ search $31,(1975) 347-364$. 